\title{
Simulation analysis of temperature field of permafrost roadbed
}

\author{
B.Li ${ }^{1234 *}$ \\ ${ }^{1}$ Tianjin Port Engineering Institute Ltd. of CCCC First Harbor Engineering Company Ltd., Tianjin, 30222 China; \\ ${ }^{2}$ Key laboratory of port geotechnical engineering, ministry of communications, PRC Tianjin, 30222 China; \\ ${ }^{3}$ Key laboratory of port geotechnical engineering of Tianjin, Tianjin, 30222 China; \\ ${ }^{4}$ CCCC First Harbor Engineering Company Ltd., Tianjin, 30222 China;
}

\begin{abstract}
The finite element analysis model of roadbed temperature field in permafrost region is established with finite element software platform. By using this model, the temperature field of roadbed is compared and analysed, and the freezing-thawing depth and variation rule of roadbed are studied. The results showed that the actual freezing depth was $1.8 \mathrm{~m}$. With the increase of the climate warming temperature, the temperature field in the roadbed changes slowly, and the temperature at different depths increases. Due to the influence of climate warming, the roadbed was in a complete positive temperature state when the maximum freezing depth appeared after 20 years. The result shown that the time of the roadbed appeared in the maximum freezing depth was earlier, the time of the roadbed in the seasonal freezing area became shorter, and the maximum freezing depth decreased.
\end{abstract}

\section{Introduction}

Frozen soil is a soil with extremely strong temperature sensitivity and instability [1-2], and its physical and mechanical properties change dramatically with the thermal disturbance of the external environment [3]. It is very important to study the variation law of subgrade temperature field to solve the road diseases in permafrost region. J rgensen et al. [4] studied the cooling effect of improved ventilation and heat dissipation embankment. Kudriavtcev et al. [5] established a finite element model to predict the change of frozen soil upper limit. Ling et al. [6] analyzed the variation rule of the thickness of permafrost non-freezing layer.

This paper analyzes the thermal stability of the subgrade by establishing the temperature field finite element model, and studies the variation rule of subgrade Frozen depth and melting depth, so as to provide theoretical reference for the construction of highways and the selection of effective protection measures for permafrost.

\section{Project overview}

Haerbin-dalian railway passenger dedicated line is the one of the highest speed of railway construction, the railway lines throughout the three northeastern provinces, the annual average temperature in the location is $4.4{ }^{\circ} \mathrm{C}$ to $10.9{ }^{\circ} \mathrm{C}$, extreme maximum temperature is $39.8{ }^{\circ} \mathrm{C}$, extreme minimum temperature can reach $-40{ }^{\circ} \mathrm{C}$, the maximum snow thickness is $30 \mathrm{~cm}$, seasonal frozen soil depth can be more than $2 \mathrm{~m}$, the ice in the roadbed will lead to settlement phenomenon, which often produce deformation of roadbed and road damage, however, The existing engineering experience (including technical standards) cannot fully meet the requirements in this regard. Under this circumstance, the study on the frozen swelling of roadbed in the seasonal frozen soil area has important economic significance and social benefits.

\section{Analysis of subgrade temperature variation}

In the seasonal frozen area, the temperature field changes due to the presence of temperature and water, leading to ice-water phase transition in soil, which has a great impact on the mechanical properties of soil. Therefore, it is very necessary to simulate the temperature field of subgrade in seasonal frozen area. In this chapter, the general finite element software ANSYS is used to simulate the variation law of subgrade temperature field, predict the variation of subgrade temperature field and the deformation trend of subgrade after many years, and put forward the preventive measures in time.

\subsection{The boundary conditions}

Because the surface of roadbed is involved in the integrated heat transfer processes such as solar radiation heat absorption, surface turbulence exchange, evaporation and condensation, etc., it is extremely complicated. Therefore, the surface temperature cannot be used as the upper boundary temperature of roadbed heat conduction calculation, so the "boundary layer principle" is introduced. The thickness of "boundary

\footnotetext{
*Corresponding author's e-mail: Lee_binbin@163.com
} 
layer" is the depth of soil layer affected by solar radiation day and night. Through theoretical estimation and longterm observation under natural conditions, the theoretical estimation and measured values of boundary layer thickness are got.

Table 1 theoretical estimation and actual observation of the thickness of the attached surface

\begin{tabular}{|c|c|c|c|}
\hline Subsurface type & $\begin{array}{l}\text { Usually moist } \\
\text { subclay }\end{array}$ & Dry gravel soil & sphalt concrete \\
\hline $\begin{array}{l}\text { Temperature coefficient } \\
\qquad \mathrm{a} \times 10^{3} /\left(\mathrm{m}^{2} / \mathrm{h}\right)\end{array}$ & 1.0 & 2.0 & 2.5 \\
\hline Theoretical estimate $/ \mathrm{cm}$ & 21 & 30 & 34 \\
\hline Long-term observations $/ \mathrm{cm}$ & 15 & 20 & 35 \\
\hline
\end{tabular}

According to the measured temperature in the test section, the upper boundary condition of roadbed is taken as the geothermal function at a depth of $0.4 \mathrm{~m}$ below the surface. Based on a lot of studies on permafrost on the qinghai-tibet plateau, the geothermal temperature is generally simulated as a positive metaphysical function.

For the left and right boundary, take the temperature gradient as zero; for the bottom, as the variation range of the ground temperature is very small, it can be taken as a constant. According to the measured data, the ground temperature at a depth of $20 \mathrm{~m}$ below the ground (bottom boundary) is taken as $2^{\circ} \mathrm{C}$.

Before the roadbed is built, the temperature when the roadbed is filled is taken as the initial temperature. In order to achieve the relative stability of the initial temperature condition, the earth temperature several years later was calculated under the above conditions, and the earth temperature at this time was taken as the initial value for the simulation analysis of the temperature field in the next 20 years.

\subsection{The section}

The height of embankment is $5 \mathrm{~m}$, and the transverse distance under the slope is $30 \mathrm{~m}$. The original foundation is $20 \mathrm{~m}$ deep, and the temperature at $20 \mathrm{~m}$ depth is considered to be basically stable. To eliminate the influence of "boundary layer", the original subgrade section $0.4 \mathrm{~m}$ below is taken as the upper surface of the calculated subgrade. The top face of embankment is $14.6 \mathrm{~m}$ wide and the bottom face is $30 \mathrm{~m}$ wide. From the top to the bottom, the foundation is divided into six layers: gravel layer, A, B material layer, cushion layer,

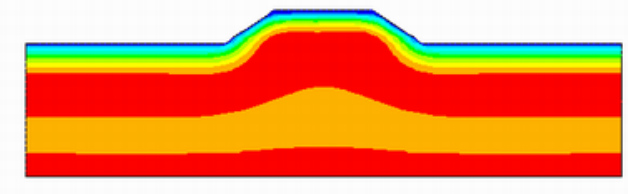

clayey loess, silty clay and medium sand. Reference test section in fuyu station roadbed practical section form, size and geological data, the calculation model is established, the graded crushed stone, A, B, mattress layer, loess, silty clay, medium sand clayey material such as soil temperature, the density, thermal conductivity of soil, soil for the parameters such as enthalpy of determined by experiment, due to space limitations, go here.

\subsection{Solving method}

The general finite element software ANSYS was used to solve the problem. Because the subgrade is long in longitudinal direction, it belongs to the problem of plane strain, so the quadrilateral 8-node element is used for grid division. The material properties of different soil elements are defined and the boundary conditions are applied on the boundary of the calculated area.

In the calculation, the temperature condition of the original surface boundary was calculated for 2 years with no temperature rise year by year to obtain the initial temperature of each point of soil within the foundation. Then the temperature constraint of the surface boundary was removed, and the temperature boundary of the new boundary after filling the roadbed was increased year by year to apply, and then 20 years were calculated.

\subsection{Results analysis}

The geothermal curves of the same date in different years are shown in figure 1 .

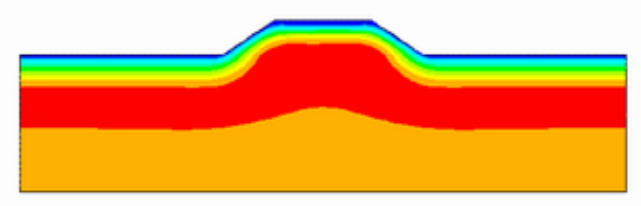

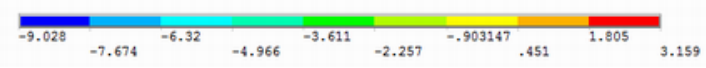

(a) 2011.1

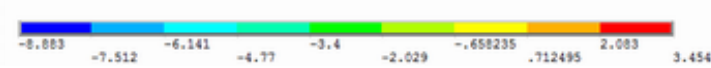

(b) 2030.1 


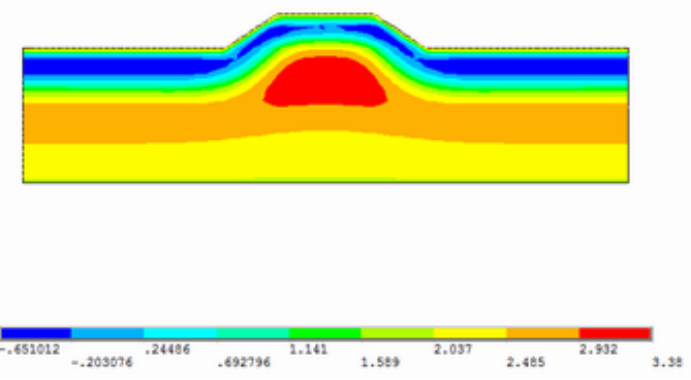

(c) 2011.4
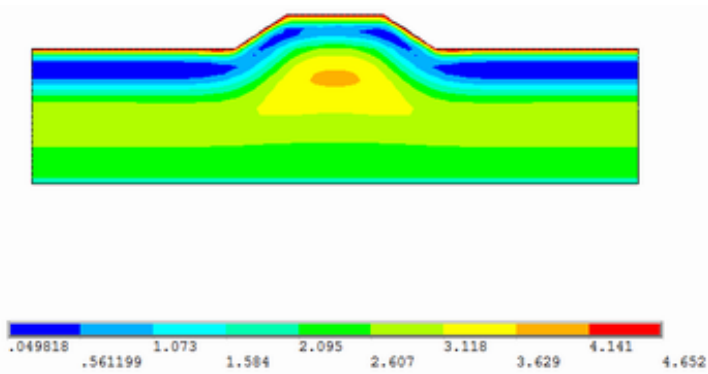

(d) 2030.4

Figure 1. temperature field distribution at each stage $\left({ }^{\circ} \mathrm{C}\right)$

Figure 1 (a) is the temperature distribution map at the end of January, 2011. It can be seen from the field observation data that the end of January is the stage with the maximum ground temperature negative temperature. It can be seen that the surface temperature of the roadbed is low, the lower it is, the higher the heat is transferring upward, and the negative temperature is transferring downward, indicating that although the surface temperature is the lowest, it is not the moment when the freezing depth is maximum. It can be seen from the comparison of (a) and (b) that, with the action of climate warming and temperature cycle, the ground temperature at all depths increased from 2011 to 2030, the temperature field was stable, and the form of the temperature field at all depths remained basically unchanged.

Figure 1 (c) shows the temperature distribution in the middle of April, 2011. It can be seen that although the surface temperature is greater than $0^{\circ} \mathrm{C}$, the internal ground temperature still has a negative temperature. At this stage, the negative temperature value is very small and is changing to a positive temperature. At this time, the freezing depth is $1.8 \mathrm{~m}$, which is basically close to the measured $1.66 \mathrm{~m}$. Figure 1 (d) shows the temperature field in the middle of April 2030. It can be seen that with the alternations of temperature cycle and the effect of climate warming, the temperature field at this stage has been completely in a state of positive temperature, indicating that the freezing time of roadbed is shortened and the maximum freezing depth is reduced.

Figure 1 (a), (b) and (c) all have the rule that the freezing depth of subgrade filler is lower than that of the original foundation, indicating that the filler has good frost resistance, which is also consistent with the measured results.

\section{Conclusion}

From the above numerical analysis, the following conclusions can be drawn:

(1) according to the numerical analysis, the simulated actual freezing depth is $1.8 \mathrm{~m}$;

(2) according to the analysis and calculation, With the increase of the climate warming temperature, the temperature field in the roadbed changes slowly, and the temperature at different depths increases. Due to the influence of climate warming, the roadbed was in a complete positive temperature state when the maximum freezing depth appeared after 20 years. The result shown that the time of the roadbed appeared in the maximum freezing depth was earlier, the time of the roadbed in the seasonal freezing area became shorter, and the maximum freezing depth decreased.

\section{References}

1. Li D Q,Chen J,Meng Q Z,et al.(2008) Numeric simulation of permafrost degradation in the eastern Tibetan Plateau. Permafrost and Periglacial Processes, 19(1): 93-99.

2. Zhang Jiupeng, Yuan Zhuoya, Wang Shuangjie, et al. (2014) Effect analysis of thaw settlement of permafrost on mechanicalresponses of pavement structure.Journal ofChangan University: Natural Science Edition, 34( 4) : 7-12.

3. Wu Q B, Shi B, Liu Y Z. (2002) Study on reciprocity of highway and permafrost along the Qinghai Tibet Highway. Science in China: Series D, 32(6): 514-520.

4. J rgensen A S, Ingeman-Nielsen T. (2012) Optimization in the use of air convection embankments for the protection of underlying permafrost. Cold regions Engineering 2012.Quebec, Canada, 12-20.

5. Kudriavtcev S, Valtseva T,Kazharskyi A,et al. (2013) Predictive modeling of the permafrost thermal regime in russian railroad subgrade support systems. Sciences in Cold and Arid Regions, 5(4): 404-407.

6. Ling F, Zhang T J. (2003) Numerical simulation of permafrost thermal regime and talik development under shallow thaw lakes on the Alaskan Arctic Coastal Plain. Journal of Geophysical research: Atmospheres, 108: 1-11. 